ENCYCLOPEDDIE Encyclopédie berbère

BERBERE

$31 \mid 2010$

31 | Matmora - Mezrag

Mérinides (Berb. : Ayt Mrin)

A. Khaneboubi

CpenEdition

Journals

Édition électronique

URL : http://journals.openedition.org/encyclopedieberbere/568

DOI : 10.4000/encyclopedieberbere.568

ISSN : 2262-7197

Éditeur

Peeters Publishers

Édition imprimée

Date de publication : 30 décembre 2010

Pagination : 4889-4895

ISBN : 978-90-429-2368-3

ISSN : 1015-7344

Référence électronique

A. Khaneboubi, « Mérinides (Berb. : Ayt Mrin) », Encyclopédie berbère [En ligne], 31 | 2010, document

M94, mis en ligne le 08 octobre 2020, consulté le 12 octobre 2020. URL : http://

journals.openedition.org/encyclopedieberbere/568 ; DOI : https://doi.org/10.4000/

encyclopedieberbere.568

Ce document a été généré automatiquement le 12 octobre 2020

(c) Tous droits réservés 


\section{Mérinides (Berb. : Ayt Mrin)}

\section{A. Khaneboubi}

1 La dynamique qui favorisa leur accession au pouvoir fut longue et complexe. Berbères zénètes* nomades originaires du Zab (Ikjān), en Ifriqiya, d'où ils furent chassés par les Arabes Banû Hilāl. au XI ${ }^{e}$ siècle, ils allèrent s'établir dans les plaines du Magrib central près de leurs cousins les Banû Badin qui étaient également parents des 'Abdalwadides. Pour s'approprier le territoire, ils durent se livrer à des guerres et furent battus parce qu'ils n'étaient pas très nombreux. Ils parcoururent la Moulouya jusqu'à Figuig et retournèrent au Zab, base à partir de laquelle leur amġār (ou amyar* : cheikh) alMukhaddab b. 'Askar (1145) lança une attaque contre un convoi almohade auquel il arracha du butin. L'almohade 'Abd al-Mu'min réagit en envoyant contre eux une armée composée de 300 cavaliers renforcés par des éléments 'abdalwadides qui le mit en déroute à Msoun, sur la rive gauche de la Moulouya. A la suite de ce revers, les rescapés retournèrent dans le désert où d'autres groupes zénètes et berbères bannis par les Almohades se joignirent à eux. Une confédération zénète s'imposa permettant aux Banû Marīn (Ayt Mrin en berbère) d'y étendre leur domination en tenant le commandement avec le titre d'émir. Cette évolution alla de pair avec leur passage du nomadisme au semi-nomadisme car ils pratiquèrent la transhumance.

2 Les auteurs du Moyen Age sont unanimes pour affirmer qu'ils firent leur apparition en 1213, aux lendemains de la grande défaite de Las Navas de Tolosa (1212) qui avait entraîné une baisse démographique dans la région. Cette situation désastreuse fut constatée par une bande (tâa'ifa) mérinide qui avait l'habitude d'estiver. Elle faisait des provisions de grains, puis s'en retournait dans son territoire de parcours au milieu de l'automne. Elle acquit une parfaite connaissance du terrain et des hommes. En 1213, elle eut la surprise de voir un pays dépeuplé, des terres abandonnées alors qu'il regorgeait de richesses. Elle apprit que la plupart des soldats avaient péri à la bataille de Las Navas de Tolosa, que l'autorité n'était plus assurée et que le pouvoir était vacant. Elle en informa les membres de leurs tribus restés dans le Zab et les invita à la rejoindre. L'opportunité d'effectuer une attaque suivie du repli était aisée, et ce, d'autant plus que les garnisons almohades ne pouvaient pas défendre la région. Les 
Mérinides arrivèrent ainsi en masse et soumirent les populations sédentaires à des taxes de protection (itāwa).

3 Ce raid fut un succès qui les incita à rester dans la région. Les émirs successifs ne se soucièrent que du prélèvement des taxes. C'est Abû Yahyā (1244-1258) qui élabora une stratégie de conquête du Mag̉rib, n'hésitant pas à distribuer des concessions iqtā' à ses pairs sous condition de former des cavaliers et des fantassins. Il voulait, selon toute vraisemblance, surmonter le handicap de l'interdit de monter et d'élever des chevaux qui avait été prononcé contre les Zénètes par le Ziride* Buluggīn* en 972.

4 L'émir mérinide investit Fès qu'il prit pour capitale, obligeant de ce fait le calife de Marrakech à se résigner à la partition du pays. Il était conscient du fait que l'acquisition $\mathrm{du}$ territoire mène au pouvoir, autrement dit que le passage du nomadisme à la sédentarisation s'effectue à travers la spoliation puis l'appropriation des terres qu'il faut repeupler.

Il était épaulé en cela par son frère Abû Yûsuf qui jouissait également de la confiance des cheikhs mérinides. Aussi n'est-il pas surprenant de le voir succéder à son frère à la tête de la confédération en tant qu'héritier présomptif. Grâce à leur aide, il investit Marrakech en 1269 où il se fit proclamer sultan. Il fonda ainsi une dynastie qui régna de 1269 à 1465 au Maġrib, soit pendant deux siècles, tout autant que les Almoravides (1061-1145) et les Almohades (1130-1269).

6 En effet, Abû Yûsuf était amgāar, fonction qui lui permit de devenir 'amīr (émir) puis sultan. Ses liens étroits avec les cheikhs qui mobilisaient les soldats de leurs clans au titre du service militaire lui conférèrent une certaine autorité, les deux parties ayant des intérêts convergents.

7 On peut diviser le règne des sultans en deux phases : celle de la stabilité qui dura un siècle et celle du déclin qui s'étala sur un autre siècle. La charnière entre ces deux périodes est constituée par l'assassinat du sultan Abû 'Inān en 1358, signe annonciateur de l'apparition de puissants vizirs/régents qui s'emparèrent du vizirat de délégation et gouvernèrent à la place de sultans qu'ils imposaient ou déposaient à leur gré. On peut mettre ces deux périodes en adéquation, mais les sultans de l'apogée semblent avoir eux-mêmes construit les instruments de leur décadence. Leurs incessantes guerres, en Andalus, à Tlemcen, en Ifrīqiya et leurs guerres de succession, confortaient leur puissance mais ruinaient le pays et vidaient les caisses de l'Etat. Cette question semble centrale pour qui étudie les modes de combat des Mérinides : leur esprit guerrier les dynamise et les affaiblit tout à la fois. Hormis les guerres de succession et les expéditions contre les tribus arabes rebelles à leur autorité, l'acquisition du territoire était leur principal objectif. Mais paradoxalement, ils étaient capables de céder du territoire pour conserver le pouvoir. Nous avons pour exemple la cession de Sijilmassa par le sultan Abû Sa'îd (1310-1331) à son fils Abû 'Ali qui était pourtant prince héritier mais était pressé de gouverner. Sans l'aide des mercenaires castillans dont le chef était son oncle maternel, le prince mérinide n'aurait pas réussi à battre son père et à lui arracher Sijilmassa.

Plusieurs facteurs, internes et externes, concoururent à l'affaiblissement de la dynastie : les guerres de succession qui avaient pour objectif la prise du pouvoir, les multiples expéditions contre les tribus arabes qui s'étaient improvisées collectrices d'impôts et les guerres livrées à l'extérieur contre les Castillans, contre Tlemcen et enfin contre Tunis. 
9 A l'instar des Almohades, le problème de la succession était récurrent chez les Mérinides bien avant l'établissement de la dynastie. Le premier sultan renonça au système d'élection élargie à l'entourage du chef qui se pratiquait chez les Zénètes et instaura une succession héréditaire. On assista alors à une concurrence des modes de succession pendant toute la durée de la dynastie suscitant un nombre élevé de prétendants qui contestaient les investitures et entraient en révolte. Le problème de la succession est né avec la dynastie et a participé à sa décadence. Il devint plus intense pendant la deuxième période à partir de la disparition du sultan Abû'Inān, en 1358. A titre d'exemple sur vingt sultans, treize furent déposés dont neuf assassinés.

10 Pour réduire la révolte de ses neveux qui avaient contesté son choix d'un prince héritier, le sultan Abùu Yusuf conseillé par les cheikhs leur proposa une sortie honorable en les envoyant en al-Andalus pour y faire la guerre sainte et ainsi canaliser leur ardeur belliqueuse. Si l'on en croit les auteurs du Moyen Age, l'idée de jihad lui tenait à cœur, c'est pourquoi il intervint quatre fois en al-Andalus remportant des succès fluctuants. Hormis l'acquisition de portions de territoire servant de bases pour son armée, il obtint le report d'une éventuelle intervention chrétienne planifiée en terre magribine. Toutefois, il n'en demeure pas moins qu'il affirma la présence mérinide comme puissance régionale pouvant porter ses attaques en terre chrétienne. Mais cette force nouvelle ne manqua pas d'inquiéter les sultans nasrides de Grenade qui préférèrent la contraignante suzeraineté castillane à la pesante menace mérinide. Aussi, les autres campagnes s'apparentèrent-elles à des ingérences plutôt qu'à un zèle religieux. Le sultan Abu l-Hasan l'apprit à ses dépens lorsqu'il subit une défaite cuisante à Tarifa en 1340 alors que la rupture avec Grenade était consommée depuis longtemps. Ne pouvant lutter à armes égales avec les Mérinides, les Nasrides contractèrent une alliance avec leurs ennemis 'abdalwadides de Tlemcen qu'ils chargeaient de les attaquer à l'Est, les empêchant ainsi de franchir le détroit.

11 Le sultan de Grenade n'ignorait pas l'antagonisme qui opposait ces deux parents zénètes qui se disputaient l'appropriation du territoire pour assurer leur parcours de nomades. Les 'Abdalwadides entrèrent au service des Almohades et combattirent dans leurs rangs. A la disparition de ces derniers, les combats qui opposaient les deux rivaux étaient directs ou consistaient en une attaque suivie du repli, mais cela tournait souvent à l'avantage des Mérinides. Ibn Khaldoun explique ces succès par leur supériorité numérique. Aussi, Yaghmurasan* qui était un homme fier avait-il dit à son successeur d'éviter d'affronter les Mérinides et de se protéger derrière les enceintes de sa ville. Cette recommandation fut suivie par ses successeurs 'Utman (1282-1303) et Abu Zayyan (1303-1308) qui soutinrent pendant plus de huit années un siège entamé par Abu Ya'qub Yusuf (1286-1307), leur capitale ne fut délivrée que par l'assassinat du sultan mérinide.

12 La dynastie ayant atteint son apogée sous le règne du sultan Abu l-Hasan (1331-1348), celui-ci ne se contenta pas d'occuper Tlemcen, il projeta d'avancer plus loin, de porter l'expansion à Tunis pour se consoler du revers subi à Tarifa. Auparavant il avait demandé conseil aux cheikhs mérinides dont il n'avait pas suivi l'avis défavorable. Son projet devint une idée fixe, ce qui fit dire à Ibn Khaldoun qu'il « voulait satisfaire une ambition qu'il nourrissait depuis longtemps ». Sans doute pensait-il reconstituer l'empire almohade. La défaite prévisible tourna à la correction à Kairouan. Son fils Abu 'Inan (1348/1351-1358) le destitua avec l'assentiment des cheikhs après lui avoir livré une guerre qu'il perdit de nouveau. A son tour, le sultan parricide commit les mêmes 
erreurs et marcha sur Kairouan malgré la mise en garde des cheikhs mérinides qui étaient las de la guerre. Ils encouragèrent leurs troupes à déserter, laissant aux Arabes le soin de le combattre. Battu, il dut lever le camp et retourner au Magrib pour mettre à mort les cheikhs qui lui avaient fait défection. Peu de temps après, il mourut assassiné par son vizir al-Fūdūdī.

13 Avec la disparition de ce sultan, nous entrons dans la deuxième phase de la dynastie, celle de la perte de la souveraineté, celle des vizirs régents. Malgré la mise sous tutelle des sultans par les vizirs, les expéditions contre Tlemcen ne furent pas interrompues. Ces vizirs s'imposèrent face aux sultans durant plusieurs titulatures, forts du soutien de leurs clans et des alliances qu'ils nouaient au gré des circonstances.

De leur côté, les cheikhs mérinides participaient activement à la prise de décisions de guerre comme à l'élaboration d'une stratégie. Grâce à eux, Abu Yusuf fut porté à la tête de la confédération mérinide et put s'imposer en tant que sultan. Le cheikh mérinide ou amgāar joue un rôle fondamental dans la gestion de son clan, fort de sa représentation auprès du sultan en tant que membre de la confédération. Enfin, il se doit de défendre les intérêts des siens ne ménageant pas ses efforts pour contribuer à leur enrichissement. Il use de son influence en équation avec l'autorité extérieure en tant que maillon de la chaîne entre l'émir ou le sultan et son clan. Il se prévaut de l'estime que lui porte le sultan, parce qu'il constitue la base du ğund, il est pourvoyeur de soldats, surtout de cavaliers. Avant la fondation de la dynastie, il incarnait le pouvoir. En s'institutionnalisant, il fit équilibre avec l'autorité centrale. La constitution de l'Etat conféra une certaine légitimité au cheikh, aussi les sultans mirent-ils en place un Conseil d'Etat (mağlis) où il siégeait avec ses pairs. Par la suite, pour atténuer leur pouvoir, les sultans intégrèrent dans ce Conseil d'autres groupes sociaux appartenant à l'élite (khașsa). Ainsi, l'assemblée archaïque des amġār évolua en entité institutionnelle. Le Conseil avait pour fonction d'entériner les investitures en leur conférant une légitimité durant la deuxième phase.

Cette période correspond à l'éclipse de l'autorité souveraine au profit de puissants vizirs régents. Le problème de la spoliation du pouvoir par les vizirs n'avait pas été prévu par les premiers sultans qui se gardaient de désigner un proche parent à cette fonction, mais ils en confiaient la charge à des membres de la confédération mérinide. Le mérite s'acquiert alors par un long apprentissage: la qualité requise étant une expérience dans la guerre ainsi que dans la capacité à récolter l'impôt. Ces vizirs qui régentaient le pays contribuèrent fortement à la chute de la dynastie, d'ailleurs elle fut supplantée par une dynastie de vizirs : les Banū Wațțās.

Un autre élément important dans l'institution mérinide est le gouverneur (wāli) qui est le double du sultan dans ses provinces. Il représente le sultan dans l'ensemble du royaume et permet d'évaluer l'importance de la cohésion de l'Etat, sachant que certains bastions sont plus difficiles à soumettre que d'autres. Les insoumis sont le plus souvent les héritiers de l'histoire passée. Par ailleurs, la fonction de gouverneur consiste également à récolter l'impôt et à lever la troupe, ce qui fait de lui la cheville guerrière et financière de l'Etat.

Quant aux aspects religieux et culturels de la dynastie, ils sont intimement liés. Les Mérinides ne connurent pas le même zèle religieux que leurs prédécesseurs, n'étant armés d'aucune idéologie. Alors que sous les Almoravides et sous les Almohades, les faqîh-s représentaient un contre-pouvoir exercé à travers leur ingérence dans les institutions, les Mérinides ne les associèrent pas à l'exercice du pouvoir et tentèrent de 
les contrôler à travers la création de madrasa-s. C'est ainsi que le premier sultan qui, bien que n'étant pas lettré et ne parlant probablement pas l'arabe puisque les sources nous disent qu'il parlait le berbère, édifia la première madrasa ou collège. Ses successeurs suivirent son exemple et $\mathrm{y}$ installèrent des étudiants boursiers d'origine campagnarde. Ces lieux d'enseignement permirent aux sultans de contrebalancer le pouvoir culturel de la cité. Ainsi, les Mérinides se révélèrent de grands bâtisseurs, en édifiant un peu plus de quinze madrasa-s sur l'ensemble de la dynastie, à partir de 1271, sur le modèle de la madrasa Nizāamiyya. Ils vont les utiliser pour contrôler l'enseignement de la théologie et renforcer le malikisme. Ces madrasa-s apparaissent comme des institutions d'Etat puisqu'elles forment des fonctionnaires et des cadres. Les cours qui y sont dispensés viennent en concurrence de ceux donnés par les faqïh-s dans les mosquées autonomes. Les madrasa-s mérinides sont aussi la manifestation d'un art architectural original et propre au Maǵrib, qu'on retrouve aussi dans les mosquées mérinides.

De même, les sultans furent à l'origine de nouvelles manifestations religieuses destinées à donner l'élan nécessaire à la vie religieuse tout en la gardant sous l'égide de l'Etat comme la fête de la Nativité du Prophète, l'illumination de la mosquée cathédrale de Fès, la nuit du 27 ramadan et l'organisation des caravanes officielles du pèlerinage à La Mecque. Les sultans ont ainsi appuyé leur marche en avant sur la religion. Les vestiges architecturaux qui subsistent dans le Maghreb contemporain témoignent de cette intense activité religieuse, culturelle et militaire.

\section{Conclusion}

19 La dynastie mérinide constitue la troisième phase monarchique de la poussée berbère au Mağrib. A l'inverse des Abdalwādides, des Ḥafșides et des Nașrides qui se déclarèrent indépendants des Almohades, elle succède à la dynastie almohade en luttant contre elle par les armes, et en même temps, elle hérite de sa structure étatique. Cet héritage réside dans la duplication et dans le perfectionnement d'institutions déjà en place. Mais, l'originalité de l'emprise des Mérinides consiste en une sorte de planification de l'occupation du territoire, précise et bien charpentée, utilisant des fonctionnaires fidèles à la dynastie et formés dans les madrasa-s. Leur capitale Fès garde les traces de leur politique culturelle agissante. La conjugaison d'usages tribaux et d'une étatisation raisonnée, donna sa configuration au royaume mérinide, fixant mœurs et mentalités au-delà d'une territorialité mouvante sans cesse remise en question par des batailles, des affrontements internes et externes à la dynastie. Le système mérinide n'accordait pas tant d'importance à l'acquisition de territoires en eux-mêmes qu'aux possibilités d'enrichissement que ceux-ci pouvaient offrir ainsi qu'aux potentialités guerrières qu'ils représentaient. On peut véritablement parler d'un système d'occupation de l'espace mettant l'esprit guerrier au service du prélèvement des taxes. 


\section{BIBLIOGRAPHIE}

IBN Al-AḤMAR (Abū l-Walid Ismā‘il), Rawḍat an-nisrīn fì dawlat Banū Marīn, al-Ribāț, 1991.

ANONYME, ad -DaHìra as-saniyya fi tāriH ad-dawla l-marīniyya, al-Ribāț, 1972. Trad. G. Bouali et G.

Marçais, Paris, 1917.

AL-ĞAZNĀ'ī (Abū l-Ḥasan'Alī), Ğannā zahrat al-ās fì binā’i madīnat Fās, al-Ribāṭ̂, 1967. Trad. A. Bel,

Alger, 1923.

IBN HुALDŪN ('Abd al-Raḥmān), al-'Ibar wa dīwān al-mubtada'wa l-Habar fi ayyām al-'arab wa l-'ağam wa l-barbar wa mā'āšarahum min ḍawī s-sulțān al-akbar, al-Qāhira, Bulāq, $1284 \mathrm{H}$, vol. VII. Trad. De Slane, Histoire des Berbères, Paris, 1982, 4 vol.

IBN Al-HАTṬīB (Lisān ad-dīn), Nufāḍat al-ğirāb fí 'ilālat al-ig̉tirāb, al-Dār al-Bayḍā', s.d.

Al-MALZūZī (Abū Fāris'Abd al-'Azīz), Naẓm as-sulūk fìl-anbiyā'wa l-Hulafā' wa l-mulūk, al-Ribāt, 1963. IBN MARZŪQ (al-Tilimsānī Muḥammad), al-Musnad așaḥịh al-ḥasan fì ma'ātir mawlānā Abī l-Ḥasan, Alger, 1981. Trad. Espagnole, M. J. Viguera, Madrid, 1977.

Al-NUMAYRİ (Ibn al-Ḥāğğ), Fayḍ al-'ubāb wa ifādat qidāh al-adab fï l-ḥaraka s-sa'ida ilā Quṣanțīna wa zZāb, Bayrūt, 1990.

KABLY M., Société, pouvoir et religion au Maroc à la fin du Moyen Age, Paris, 1986.

KHANEBOUBI A., Les premiers sultans mérinides, histoire politique et sociale, Paris, 1987.

KHANEBOUBI A., Les institutions gouvernementales sous les Mérinides, Paris, 2008.

LAROUI A., L'histoire du Maghreb : un essai de synthèse, Paris, 1976.

Shatzmiller M., L'historiographie mérinide. Ibn Khaldoun et ses contemporains, Leiden, 1982.

Al-'UMARĪ (Ibn Faḍlallāh), Masālik al-abșār fi mamālik al-amșār, al-Dār al-Bayḍa', 1988. Trad. M.

Gaudefroy-Demombynes, Paris, 1927.

Al-WANŠARĪsī (Abū l-'Abbās Aḥmad), al-Mi'yār al-mu'rib wa l-ǧāmi' al-muġrib fĭ fatāwī ahl Ifrìqiyā wa lAndalus wa l-Magrib, al-Ribāṭ/Bayrūt, 1981, 13 vol.

IBN Abī ZAR' ('Alī), al-Anīs al-muțrib bi rawḍ al-qarțās fỉ aHbār milūk al-Mag̉rib wa tārīH madīnat Fās, alRibāṭ, 1973.

INDEX

Mots-clés : Maroc, Moyen Âge 